\title{
How Psychological Capital Promotes Innovative Behavior: A Mutilevel Modeling
}

\author{
Xiling Lan \\ Department of Business Management, College of Business Administration, South China University of Technology, Guangzhou, \\ China \\ Email: kailanglxl@163.com
}

How to cite this paper: Lan, X.L. (2019) How Psychological Capital Promotes Innovative Behavior: A Mutilevel Modeling. American Journal of Industrial and Business Management, 9, 2202-2219. https://doi.org/10.4236/ajibm.2019.912146

Received: November 15, 2019

Accepted: December 16, 2019

Published: December 19, 2019

Copyright (c) 2019 by author(s) and Scientific Research Publishing Inc. This work is licensed under the Creative Commons Attribution International License (CC BY 4.0).

http://creativecommons.org/licenses/by/4.0/

\section{(c) (i) Open Access}

\begin{abstract}
Based on conservation of resources theory, this study explores the impact of employee psychological capital on innovative behavior and the role of job embeddedness and internal social capital in this process. The results of cross-level data analysis show that psychological capital can effectively predict employee innovative behavior; psychological capital predicts employee innovative behavior through job embeddedness; internal social capital not only moderates the impact of psychological capital on job embeddedness, but also moderates the indirect relationship of psychological capital affecting innovative behavior through job embeddedness. The results of this study reveal the underlying mechanisms of how employees' psychological capital drive innovative behavior from the perspective of social relationships resources and provide new ideas for effectively guiding enterprise innovation management practice.
\end{abstract}

\section{Keywords}

Psychological Capital, Internal Social Capital, Job Embeddedness, Innovative Behavior

\section{Introduction}

With the globalization of competition and the advent of the cloud computing internet era, continuous innovation has become an important tactic for enterprises to cope with dynamic and complex changes [1]. As a unique organizational asset, the success of an organization is increasingly inseparable from the creativity and innovative behavior of employees at work [2], so how to effectively inspire employees' innovative behavior has always been an important issue of concern in the theoretical and practical circles and has led to a lot of researches. 
Throughout this research, more and more researches have been conducted on the relationship between individual psychological capital and innovative behavior in recent years [3] [4]. Psychological capital mainly refers to the positive state of psychological development at the individual level [5], and studies have been conducted from cognition [6] [7], emotions [8] and behavior [9] to explore the impact of psychological capital on innovation behavior, but less on the perspective of social relationships. According to conservation of resources theory, relationships as an important aspect of an individual's available resources greatly affect individual behavior [10].

Job embeddedness reflects the relationship between employees and organizations, mainly about the collection of various elements that prevent employees from leaving the organization [11]. The higher the level of embeddedness between employees and organizations means that the relationship between employees and their surroundings, including colleagues, will be closer, the environment in which employees work will be more matched and adapted and the more sacrifices will arise if employees leave the current working environment [12]. Past researches have found that job embeddedness has a positive predictive effect on individual attitudes and subsequent behavioral performance [13] [14] [15]. Individuals with high psychological capital, in order to obtain more resources, will enhance their ties with colleagues, improve the matching between individuals and organizations, and show more organizational behavior, so this study suggests that psychological capital may affect employee's innovative behavior via the mediating effect of job embeddedness.

In addition to the fact that job embeddedness affects an individual's innovative behavior, the relationship between the individual and the team may also be an important factor affecting their innovative behavior. Internal social capital reflects the capital associated with the organization's internal relationships and can contribute to the achievement of organizational members' goals [16]. Studies have shown that this variable greatly affects the relationship between individuals and work and subsequent behavioral performance [17] [18]. Whereas the high internal social capital, informal relations of internal members were originally high, members have common values and visions. Under pressure, employees with high psychological capital believe in corporate decision-making, and are more willing to maintain close relationships with the enterprise and show more behaviors that are in line with the interests of the company. Therefore, this study considers the higher the internal social capital, the more the employee's psychological capital may affect the innovative behavior through job embeddedness.

In short, based on conservation of resources theory, this study is from the perspective of relational resources and incorporates job embeddedness and internal social capital to explore how the interaction between psychological capital and internal social capital affects the innovative behavior of employees. Our research makes several important contributions, such that, our research will help clarify underlying mechanisms of how employees' psychological capital drive 
innovative behavior, on the other hand, our research can effectively guide the practice of innovation management.

\section{Theory and Hypotheses}

\subsection{The Effects of Psychological Capital on Innovative Behavior}

Psychological capital is broadly defined as a positive psychological development state, characterized by self-efficacy, hope, optimism and resiliency at the individual level. Specifically, self-efficacy means having confidence and effort to complete difficult tasks, optimism refers to the positive attribution of success to the present and positive expectations for future success. Hope means insisting on the goal and, if necessary, to find a way to achieve the goal. Resiliency refers to adapt and rebound even beyond stress to achieve success under problems and setbacks [19] [20]. Consistent with conservation of resources theory, individuals have the motivation to protect their existing resources and acquire new resources [21]. We suggest that as a kind of personal resource [22], psychological capital not only has an intrinsic incentive for employees, such that individuals with high psychological capital can better resist work stress and it is not easy to cause emotional exhaustion, but also gives rise to incentive gains, improve individual motivation and job performance [22] [23]. Past research suggests that psychological capital positively affects employees' positive attitudes and positive behaviors [24], such as career well-being [25] [26], organizational commitment and organizational citizenship behavior [27] [28]. Innovative behavior is a provocative and challenging role-external behavior, reflecting the individual's willingness to change his or her current situation, including the formation, promotion and implementation of innovative ideas [29] [30]. Specifically, innovative measures are often accompanied by high risks and uncertainties. Individuals with high psychological strength are required to advance. Innovation challenges require employees to cope with self-efficacy. The innovation process requires employees to be full of hope. Innovation results require employees to be optimistic. Innovation pressure requires employees to be resiliency. Therefore this study proposes the following:

Hypothesis 1: Psychological capital is positively related to innovative behavior.

\subsection{Job Embeddedness as a Mediator}

Job embeddedness mainly refers to the degree of fit between employees and organizations [31]. It is generally believed that job embeddedness is mainly composed of three dimensions: 1) links reflect various formal or informal relationships between employees and organizations; 2) fit refers to the degree of matching and compatibility with interests and values of the organization which perceived by employees; and 3) sacrifice refers to the material and psychological losses that employees face when leaving the current organization [11]. Studies have shown that job embeddedness is not only effective in predicting employee turnover intentions and turnover behavior [11], but also effectively explains em- 
ployee performance and organizational citizenship behavior [14] [32].

According to conservation of resources theory, in order to obtain additional resources, psychological capital is invested as an effective resource in positive role behavior [33]. First, optimistic and hopeful employees believe that the problems encountered at work can always be solved [5], and they are also optimistic about the future development of the organization, so it is more likely to have a love for the organization. Second, in order to increase their connection with the organization, they are also more willing to establish formal or informal relationships with organizations to make their social networks more compact [11]. Finally, employees whit high self-efficacy, hope and resiliency are more willing to devote themselves to their current work [5], and are more willing to proactively improve their match with the organization to adapt to the organizational environment. Therefore this study proposes the following:

Hypothesis 2a: Psychological capital significantly positively affects job embeddedness.

Secondly, Halbesleben et al. [34] first defined job embeddedness as a rich resource for employees, including 1) links is a kind of relationship resource of employees; 2) fit means the consistency of employee's career goals and values with work requirements and organizational culture; 3) sacrifice reflects the importance principle of preventing resource loss in conservation of resources theory. Employees with a higher level of job embeddedness represent a greater degree of association and compatibility with their organization, and a greater loss of resources if they abandon their current work [11]. In accordance with conservation of resources theory, if the level of job embeddedness is increased, employees will be more willing to take the initiative to show positive role behaviors to show the value of the organization to ensure that their current job returns are not reduced and strengthen their employment security (resource protection) [35]. As a role outside behavior of forming, promoting and applying new ideas, innovative behavior is often seen as a positive expression of organizational citizenship behavior, making it easier to obtain higher performance evaluations (resources) [36]. Based on this, employees with a high level of job embeddedness are more willing to acquire valuable resources by implementing innovative behaviors. Therefore this study proposes the following:

Hypothesis $2 \mathrm{~b}$ : Job embeddedness significantly positively affects innovative behavior.

Furthermore, individuals with high psychological capital have more trait resources. So they are more resistant to stress, and are less vulnerable to resource loss. In the context of encouraging innovation, in order to obtain more resource reserves, it is wise to adapt to the company's policies, to choose the behavior that is most beneficial to themselves, to conduct more interaction with the colleagues of the company, to actively adjust themselves to match the organization, to stand on the same line with the organization at the critical moment, to actively cooperate with the development of the enterprise's innovation work, and to propose 
innovative ideas and show innovative behavior. Therefore this study proposes the following:

Hypothesis 2c: Job embeddedness plays a mediating role in the relationship between psychological capital and innovative behavior.

\subsection{Internal Social Capital as a Moderator}

Social capital, as a manifestation of social associations, arises from the social relationships embedded in organizations or individuals and it can be embodied in social networks [37] and it contains shared values, norms and trusts in social networks [38]. Contrary to the external social capital formed by external social relations, internal social capital is generated by the internal bond of the organization, which can promote organizational coordination and mutually beneficial cooperation [39], giving the organization cohesiveness and promoting the achievement of the overall goal of the organization [17]. Literature studies show that corporate internal social capital can promote product innovation [40], organizational performance [41] [42] and knowledge flow [43].

As a positive psychological resource, psychological capital can play an important role in relieving individual stress [44] [45]. Base on conservation of resources theory, in the face of pressure, employees often look for opportunities to maintain and actively acquire new resources. Internal social capital stabilizes a wide range of internal social networks, trust-regulated interpersonal relationships and a consistent organizational culture and vision [18] which can enable employees to better access the resources they need [46]. Therefore, this study suggests that internal social capital can moderate the impact of psychological capital on job embeddedness. Specifically, a higher internal social capital level means that the social network structure within the organization is tight, extensive and stable, and the flow of information between employees is rapid and frequent. Network members can effectively avoid information risks, so the team is confident, hopeful, and optimistic. Resilience employees are more willing to form a close social network connection with the organization based on the purpose of obtaining resource increments, which is conducive to enhancing job embeddedness. In addition, high internal social capital teams share common values and visions, and members trust and recognize each other and can help each other in their work, thereby enhancing employees' perception of resource accessibility in social networks within the organization and promoting employee job embeddedness to get resources. Third, because high-quality internal social environment can promote the rapid integration of employees, employees in high internal social capital organizations will lose more when they leave the organization, which will result in stronger willingness than the organization of low internal social capital to stay in the organization. According to conservation of resources theory, if an organization can provide employees with the required work environment and corresponding work resources, employees will be more willing to establish a firm and close relationship with the organization [47]. In light of 
these arguments, compared with the organization of low internal social capital, the impact of employee psychological capital on job embeddedness is stronger under high internal social capital conditions. Therefore, this study proposes the following:

Hypothesis 3a: Internal social capital moderates the relationship between psychological capital and job embeddedness such that the relationship is stronger when the internal social capital is higher versus lower.

Furthermore, in the organization of high internal social capital, employee psychological capital has a stronger role in promoting job embeddedness. High job embeddedness makes employees quickly familiar with organizational work procedures, masters the learning system, and is more adept at discovering organizational problems. And high job embeddedness makes it easier to obtain effective information and communicate with people, so the generation, promotion and practice of employee innovation ideas are easier to carry out. In contrast, in the organization of low internal social capital, psychological capital has a weak promotion effect on job embeddedness. The lower job embeddedness makes the connection between employees and organizations loose. The overall values and goals of the organization cannot be closely consistent with the employees, while the individual leaves the organization. The losses that will be faced are also small, so employees tend to be more alienated from the organization, and the willingness to find problems and engage in innovative thinking and practice is smaller. Therefore this study proposes the following:

Hypothesis 3b: The indirect effect of psychological capital on innovative behavior via job embeddedness is moderated by internal social capital such that the indirect effect is stronger when internal social capital is higher versus lower.

Theoretical model of this study is shown in Figure 1.

\section{Method}

\subsection{Sample and Procedures}

This study used a multi-source and paired tracking questionnaire to collect data from the South China region. Business leaders come from EMBA and MBA students who have graduated from a business school and have graduated or are connected through other collaborative projects. Contact the randomly selected sample leader by telephone, email, etc., and obtain the contact information of

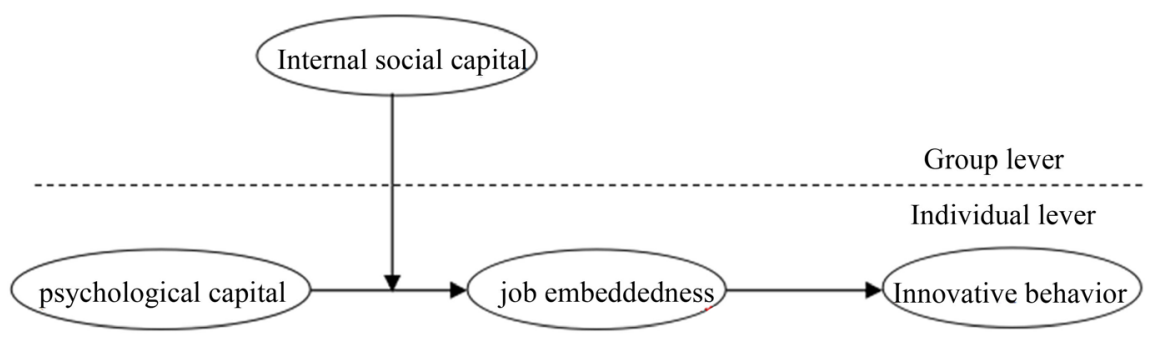

Figure 1. Theoretical model of this study. 
the randomly provided employees with their consent to carry out further research. In order to reduce the common method biases, the study obtained data at three-time points, each time interval is three months, the first survey collected data on the internal social capital of the variable filled by the leader; the second survey collected data on variable psychological capital and job embeddedness filled out by the direct employees of the leader; the third survey collected data on variable innovative behavior filled out by employee leaders. In this survey, there were 76 leaders and 379 employees. Excluding invalid questionnaires and mismatched questionnaires, 66 leaders and 106 pairs of leaders and employees were matched. The recovery ratio reached $77.3 \%$. The demographic characteristics of the sample are as follows:

In leaders: gender, $59.1 \%$ male, $40.9 \%$ female; age, $28.8 \%$ under $30,25.8 \%$ at $31-35,21.2 \%$ at $36-40,24.2 \%$ at 41 and above; education level, $71.2 \%$ of undergraduate and above; working years, $9.1 \%$ in 4 years and below, $24.2 \%$ in $5-7$ years, $22.7 \%$ in 8 - 10 years, $43.9 \%$ in 10 years and above; position level, $31.8 \%$ of grassroots leaders, $30.3 \%$ of middle leaders, $37.9 \%$ of senior leaders.

Among employees: gender, $44.7 \%$ male, $55.3 \%$ female; age, $57.3 \%$ under 30 , $27.6 \%$ at $31-35,10.2 \%$ at $36-40,4.8 \%$ at 41 and above; education level, $20.5 \%$ of high school and below, $37.2 \%$ of junior college, $24.9 \%$ of undergraduate, $17.4 \%$ of master's degree and above; working years, $17.7 \%$ in 2 years and below, $20.1 \%$ in $2-4$ years, $28.0 \%$ in $5-7$ years, $8 \%-15.4 \%$ in $8-10$ years, $18.8 \%$ in 10 years and above; position level, $62.1 \%$ of ordinary employees, $25.9 \%$ of grassroots managers, $11.9 \%$ of middle managers and above; working time with leaders, $27.3 \%$ below 1 year, $23.5 \%$ in $1-2$ years, $15.7 \%$ in 2 - 3 years, $19.1 \%$ in $3-5$ years, $14.3 \%$ in 5 years and above.

\subsection{Measures}

In order to ensure the reliability and validity of the measured variables, this study used the maturity scale used in the previous literature. A two-way translation program was used for the English scale [48], and Chinese translations were repeatedly considered and modified to ensure a more accurate representation of the original scale. At the same time, the reliability and validity of the measurement scale used were examined. The Cronbach's $\alpha$ value is usually used to test the reliability of the measurement scale. The general Cronbach's $\alpha$ value is greater than 0.7 , indicating that the reliability of the meter reaches an acceptable level [49]. Through the confirmatory factor analysis (CFA) test scale validity, the fitting index used in this study and the well-fitted judgment criteria are as follows: the chi-square degree of freedom ratio $\left(\chi^{2} / \mathrm{df}\right)$ is less than 2 and it is acceptable when less than 5 ; the comparative fit index (CFI) is greater than 0.9; the Tucker-Lewis index (TLI) is greater than 0.9 ; the standardized root mean square residual (SRMR) is less than 0.08; root mean square error of approximation (RMSEA) is less than 0.08 [50].

Psychological Capital. Twenty four items developed by Luthans et al. were 
used [5]. Sample items are "I feel confident analyzing a long-term problem to find a solution", and "There are lots of ways around any problem". Reliability analysis showed that the Cronbach's $\alpha$ value of the scale was 0.82 ; the confirmatory factor analysis showed that the scale of $\chi^{2} / \mathrm{df}=1.54$, CFI $=0.92$, TLI $=0.90$, SRMR $=0.05$, RMSEA $=0.04$, both reached acceptable level.

Job Embeddedness. Seven items developed by Crossley et al. were used [32]. Sample item is "I am tightly connected to this organization". Reliability analysis showed that the Cronbach's $\alpha$ value of the scale was 0.71 ; the confirmatory factor analysis showed that the scale of $\chi^{2} / \mathrm{df}=2.12, \mathrm{CFI}=0.97$, TLI $=0.94, \mathrm{SRMR}=$ 0.04 , RMSEA $=0.06$, both reached acceptable level.

Innovative Behavior. Six-item scale developed by Scott et al. was used [51]. Sample item is "This subordinate can generates creative ideas". Reliability analysis showed that the Cronbach's $\alpha$ value of the scale was 0.88 ; the confirmatory factor analysis showed that the scale of $\chi^{2} / \mathrm{df}=2.76, \mathrm{CFI}=0.98$, TLI $=0.97$, SRMR $=0.02$, RMSEA $=0.08$, both reached acceptable level.

Internal Social Capital. Seven-item scale developed by Reed et al. was used [52]. Sample item is "How adequately do your employees share information and learn from one another". Reliability analysis showed that the Cronbach's $\alpha$ value of the scale was 0.70 ; the confirmatory factor analysis showed that the scale $\chi^{2} / \mathrm{df}$ $=1.45, \mathrm{CFI}=0.998, \mathrm{TLI}=0.99, \mathrm{SRMR}=0.03, \mathrm{RMSEA}=0.04$, both reached accepted level.

Control Variables. In order to exclude the influence of other factors, we control the personal characteristics that may affect employees' psychological capital, job embeddedness and innovative behavior, including demographic variables such as gender and age.

The above scales all use the Likert 5 point method, 1 means "very disagree", 5 means "very agree", and the statistical analysis software used is Mplus7.4 and SPSS 23.0.

\section{Discriminant Validity Analysis Test between Variables}

The common method bias was tested by Harman's one-factor test, and the results of unrotated factor analysis were obtained by exploratory factor analysis (EFA). If there are the following two cases: either only precipitation factor or the interpretation of the first factor is very strong, it can be concluded that the common method bias is not effectively controlled [53]. The results showed that a total of 13 factors were precipitated, and the first factor before the rotation explained $17.84 \%$ of all the variation, which was much lower than half of the total variation explained, indicating that the common method bias was controlled effectively in this study.

At the same time, the confirmatory factor analysis (CFA) is used to test the discriminant validity between the variables. The fitting indicators are shown in Table 1. As can be seen from Table 1, the fitting indicators of the four-factor model are better than the other three models, it shows that the discriminant validity of each variable in this study is better. 
Table 1. Confirmatory factor analysis results.

\begin{tabular}{cccccccc}
\hline & $\chi^{2}$ & $\mathrm{df}$ & $\chi^{2} / \mathrm{df}$ & CFI & TLI & RMSEA & SRMR \\
\hline Four-factor model & 1187.54 & 884 & 1.34 & 0.91 & 0.90 & 0.04 & 0.06 \\
Three-factor model & 1563.04 & 887 & 1.76 & 0.83 & 0.82 & 0.05 & 0.07 \\
Two-factor model & 1892.67 & 889 & 2.13 & 0.76 & 0.74 & 0.06 & 0.09 \\
Single factor model & 2528.91 & 890 & 2.84 & 0.61 & 0.58 & 0.08 & 0.09 \\
\hline
\end{tabular}

Note: Four-factor model: psychological capital; job embeddedness; innovative behavior; internal social capital; Three-factor model: psychological capital + internal social capital; job embeddedness; innovative behavior; Two-factor model: psychological capital; job embeddedness + innovative behavior + internal social capital; Single-factor model: psychological capital + job embeddedness + innovative behavior + internal social capital.

\section{Results}

\subsection{Descriptive Statistical Analysis Results}

The means, standard deviations, correlations and Cronbach's $\alpha$ value of the variables involved in this study are shown in Table 2. The data showed that psychological capital was positively correlated with job embeddedness, and the effect value was significant $(r=0.45, \mathrm{p}<0.01)$. Psychological capital was positively correlated with innovative behavior, and the effect value was significant $(\mathrm{r}=$ $0.24, \mathrm{p}<0.01)$. Job embeddedness is also positively correlated with the innovative behavior, and the effect value is also significant $(\mathrm{r}=0.21, \mathrm{p}<0.01)$. The descriptive statistical analysis results preliminarily indicate that there is a relationship between the variables as assumed, indicating that further hypothesis testing can be performed.

\subsection{Hypothesis Test}

We used the multi-level model (MLM) and Monte Carlo (MC) 95\% confidence interval estimation method to test the hypothesis, and obtained Table 3. As expected, the results show that the psychological capital significantly positively af fects the innovative behavior $(\gamma=0.28, \mathrm{p}<0.05)$. Thus, hypothesis 1 is supported. Psychological capital significantly positively affects job embeddedness $(\gamma$ $=0.60, \mathrm{p}<0.001)$. Thus, hypothesis $2 \mathrm{a}$ is supported. Job embeddedness significantly positively affects innovative behavior $(\gamma=0.27, \mathrm{p}<0.01)$. Thus, hypothesis $2 \mathrm{~b}$ is supported. Whereas, the direct effect of psychological capital on innovative behavior is not significant $(\gamma=0.12, \mathrm{p}>0.05)$, the indirect effect mediated by job embeddedness of psychological capital on innovative behavior is significant $(\gamma=0.16, \mathrm{p}<0.05)$, indicating job embeddedness plays a fully intermediary role. Thus, hypothesis $2 \mathrm{c}$ is supported. To further test mediation effect, we conduct Monte Carlo test. The result shows that the 95\% confidence interval of the intermediate path do not contain $0(\mathrm{LLCI}=0.04, \mathrm{ULCI}=0.31)$. Thus, hypothesis $2 c$ is further supported.

In addition, internal social capital significantly positively moderates the impact of psychological capital on job embeddedness $(\gamma=0.64, \mathrm{p}<0.05)$. Thus, 
Table 2. Means, standard deviations, and correlations $(\mathrm{N}=293)$.

\begin{tabular}{lcccccccccc}
\hline & 1 & 2 & 3 & 4 & 5 & 6 & 7 & 8 & 9 & 10 \\
\hline 1) gender & - & & & & & & & & & \\
2) age & $-0.20^{* *}$ & - & & & & & & & & \\
3) education level & 0.11 & $0.12^{*}$ & - & & & & & & \\
4) working years & -0.08 & $0.68^{* *}$ & 0.10 & - & & & & & & \\
5) position level & $-0.20^{* *}$ & $0.36^{* *}$ & $-0.19^{* *}$ & $0.44^{* *}$ & - & & & & \\
6) working time with & -0.08 & $0.41^{* *}$ & 0.10 & $0.45^{* *}$ & $0.30^{* *}$ & - & & & & \\
leaders & & & & & & & & & & \\
7) psychological capital & -0.07 & -0.02 & $0.12^{*}$ & -0.04 & -0.02 & -0.06 & $(0.82)$ & & & \\
8) job embeddedness & 0.09 & -0.03 & 0.03 & $-0.14^{*}$ & -0.10 & -0.06 & $0.45^{* *}$ & $(0.71)$ & & \\
9) innovative behavior & 0.06 & -0.05 & $0.24^{* *}$ & $-0.16^{* *}-0.13^{*}$ & -0.03 & $0.24^{* *}$ & $0.21^{* *}$ & $(0.88)$ & \\
10) internal social & -0.03 & -0.04 & $0.15^{*}$ & -0.09 & $-0.13^{*}$ & -0.00 & $0.23^{* *}$ & $0.30^{* *}$ & $0.33^{* *}$ & $(0.70)$ \\
capital & & & & & & & & & & \\
M & 1.55 & 2.47 & 2.40 & 2.97 & 1.50 & 2.69 & 3.88 & 3.52 & 3.44 & 3.75 \\
SD & 0.50 & 1.06 & 1.00 & 1.35 & 0.72 & 1.42 & 0.32 & 0.47 & 0.73 & 0.46 \\
\hline
\end{tabular}

Note: ${ }^{*} \mathrm{p}<0.01 ;{ }^{*} \mathrm{p}<0.05$. The blackened number is the Cronbach's $\alpha$ value.

Table 3. MLM model path coefficient.

\begin{tabular}{cccc}
\hline path & Coefficient (standard deviation) & path & Coefficient (standard deviation) \\
\hline a & $0.60^{* * *}(0.14)$ & e1 & $0.03(0.10)$ \\
b & $0.27^{\star *}(0.11)$ & e2 & $0.04(0.05)$ \\
c & $0.12(0.16)$ & e3 & $0.18^{* *}(0.07)$ \\
i & $0.64^{*}(0.25)$ & e4 & $-0.11^{\star *}(0.04)$ \\
Mediating effect & $0.16^{*}(0.07)$ & e5 & $-0.00(0.07)$ \\
Total effect & $0.28^{*}(0.13)$ & e6 & $0.02(0.03)$ \\
\hline
\end{tabular}

Note: ${ }^{* * *} \mathrm{p}<0.001 ;^{* *} \mathrm{p}<0.01 ;^{*} \mathrm{p}<0.05$. a indicates the action path of psychological capital on job embeddedness; $b$ indicates the action path of job embeddedness on innovative behavior; $c$ indicates the action path of psychological capital on innovation behavior; i indicates the moderator effect of internal social capital on path a; e1 - e6 respectively represent the path of demographic variables to innovative behavior.

hypothesis $3 \mathrm{a}$ is supported. In order to more intuitively show the moderating effect of internal social capital on path a, researchers draw the relationship between psychological capital and job embeddedness under different conditions of internal social capital under the mean of adding and subtracting one standard deviation. It can be seen from Figure 2 that when the internal social capital is higher than the mean standard deviation, the positive impact of psychological capital on job embeddedness is significant $(\beta=0.89, \mathrm{p}<0.001)$. In contrast, when the internal social capital is below the mean by one standard deviation, the positive impact of psychological capital on job embeddedness is not significant $(\beta=0.31, \mathrm{p}>0.05)$. At the same time, the difference is significant $(\beta=0.58, \mathrm{p}<$ 0.05). Thus, hypothesis $3 \mathrm{a}$ is further supported. 


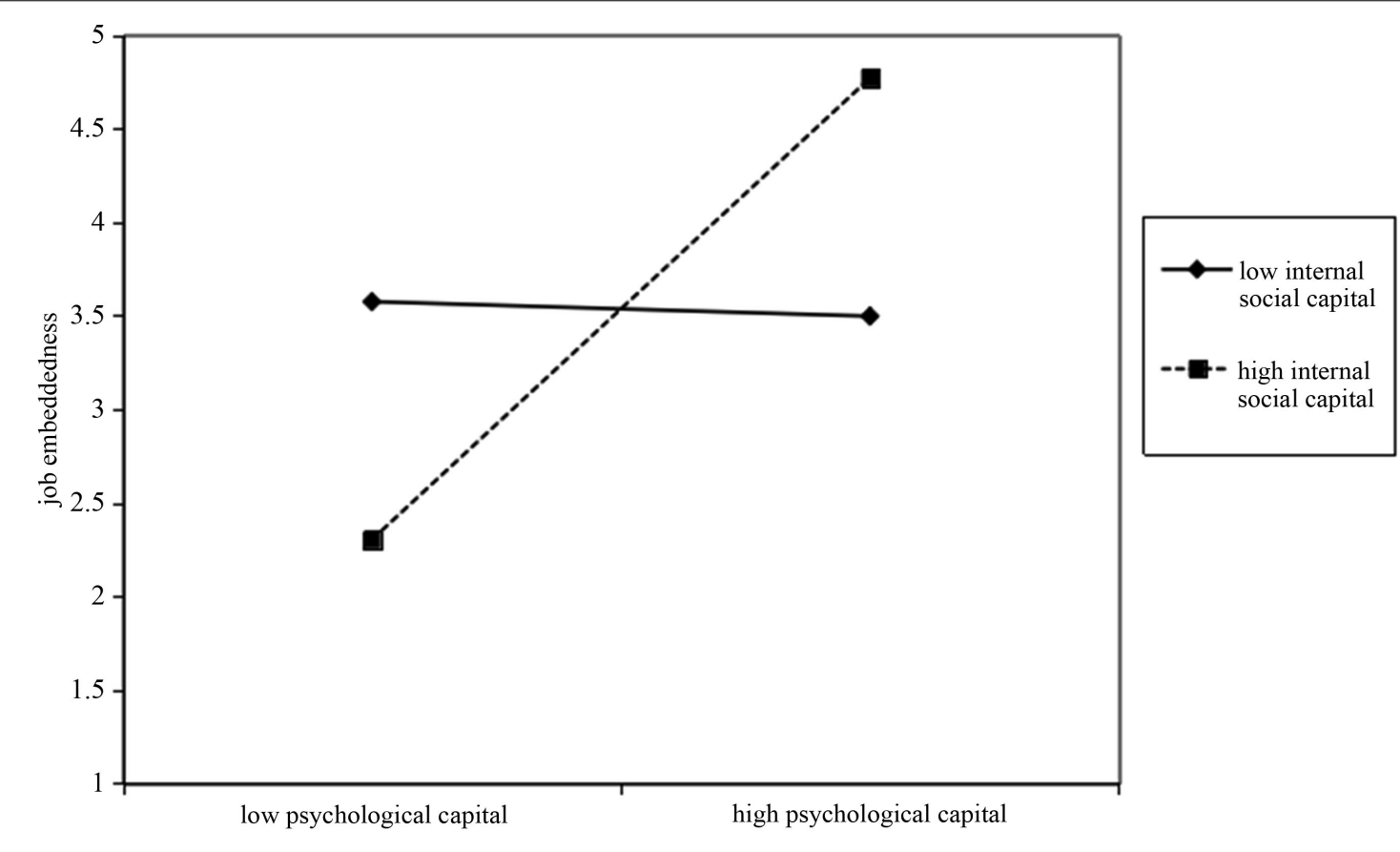

Figure 2. The moderating role of internal social capital.

Further MC simulation test shows the significance of moderated mediation effect. It can be seen from Table 4 that under the higher level of internal social capital, the indirect effect value of psychological capital on innovation behavior through job embeddedness is $0.24 \%$ and $95 \%$ confidence interval does not contain 0 (LLCI $=0.06$, ULCI $=0.43)$, indicating the effect value is significant. Under the low level of internal social capital, the indirect effect value of psychological capital on innovation behavior through job embeddedness is $0.08 \%$ and $95 \%$ confidence interval contains $0(\mathrm{LLCI}=-0.05, \mathrm{ULCI}=0.24)$, indicating the effect value is not significant. The high and low difference effect value is 0.16 and the $95 \%$ confidence interval does not contain 0 (LLCI $=0.01$, ULCI $=0.38)$, indicating the effect value is significant. Therefore, hypothesis $3 \mathrm{~b}$ is supported.

\section{General Discussion}

Organizational change and development are inseparable from employee innovation. How to make employees actively propose innovative ideas and show more innovative behaviors is one of the issues that current leaders should consider. Based on conservation of resources theory, this study explores how psychological capital interacts with internal social capital to stimulate employees to perform more innovative behaviors from the perspective of relational resources, and further explores how psychological capital affects innovative behaviors via job embeddedness and how the organizational factors-internal social capital moderates in this process, multilevel model analysis and Monte Carlo confidence interval estimation method analysis results support the hypothesis of this study. 
Table 4. MC test for the moderated mediator effect.

\begin{tabular}{lcccc}
\hline \multirow{2}{*}{ Result variable } & internal social capital & Effect value & \multicolumn{2}{c}{$95 \%$ Confidence interval } \\
\cline { 4 - 5 } & High level & 0.24 & 0.06 & 0.43 \\
& Low level & 0.08 & -0.05 & 0.24 \\
innovative behavior limit & Upper limit \\
\cline { 3 - 5 } & High and low difference & 0.16 & 0.01 & 0.38 \\
\hline
\end{tabular}

Note: If the interval between the lower limit and the upper limit does not include 0 , the effect is significant, otherwise it is not significant.

\subsection{Theoretical Contribution}

First, this study has deepened the internal mechanism of employee psychological capital affecting its innovative behavior to a certain extent. Previous researches on the relationship between psychological capital and individual innovative behavior have mostly started from the perspectives of cognition, emotion, and behavior. Based on conservation of resources theory, this study explores the impact of psychological capital on employee innovative behavior from the perspective of relational resources, and provides a new theoretical perspective for the study of psychological capital. At the same time, the researcher incorporates job embeddedness into the research framework of psychological capital affecting individual behavior, and verifies the mediating effect of job embeddedness. Psychological capital will stimulate employee innovative behavior by affecting subordinate job embeddedness. The research results not only enrich the mechanism of psychological capital research on individual behavior, but also provide a new theoretical perspective for the study of psychological capital and individual innovative behavior.

Second, this study expands the explanatory power of conservation of resources theory in the generation of innovative behavior by portraying the role of internal social capital in the relationship between psychological capital and innovative behavior. Specifically, based on conservation of resources theory, this study combines individual psychological capital with internal social capital by introducing the moderator variable internal social capital, and explores and tests the synergistic effects of psychological capital and internal social capital on individual innovation behavior, then empirically verifies it, in turn, the moderating mechanism of internal social capital in the process of psychological capital affecting innovative behavior via job embeddedness further clarifies the boundary conditions in this process, which is not only conducive to understanding the driving mechanism of individual innovation behavior, but also provide a certain theoretical basis to promote enterprise innovation.

Thirdly, previous studies have explored the impact of psychological capital on individual emotions, attitudes and behaviors from an individual level, and studied the relationship between psychological capital and individual emotions and individual behaviors. However, due to the influence mechanism of psychological capital and the boundary conditions of psychological capital affecting individual 
behavior, it will be affected by different levels of variables such as specific culture or institutional background [54], so explore the multi-level research and cross-culture research of psychological capital are necessary. On the other hand, most of the existing research methods use cross-sectional research and this research paradigm has obvious problems in the verification of variable causality. This study is based on the Chinese situation, through time-phased and multi-source data collection methods. Cross-level statistical methods were used to process data. To a certain extent, it guarantees the accuracy and objectivity of the research results, and at the same time expands the application of the theory of psychological capital.

\subsection{Practical Value}

This study explores the impact mechanism of employee psychological capital on innovative behavior, and provides the following inspiration for enterprise innovation management. First, enterprises should pay attention to the examination of employees' psychological capital in the process of organizing recruitment, focusing on the talents with higher psychological capital. At the same time, enterprises should pay attention to the creation and maintenance of the internal innovation atmosphere, and timely provide care and psychological counseling when employees are lack of enthusiasm and innovative confidence, so that employees' innovative behavior can be maintained. Second, pay attention to and improve the level of employee job embeddedness. Enterprises can appropriately organize employees or new employees to conduct centralized learning training, so that employees can clearly understand their organizational roles and accept the values and abilities required by the organization, in turn, employees can better understand themselves, understand the organization, fit better with the organization, pay more attention to the development of the organization, closely link their progress with the development of the organization, and ultimately make the employee's behavior meet the expectations of the organization's development. Third, effectively strengthen the internal social capital in the enterprise through informal regulations and communication. Enterprises should create a relaxed and harmonious team atmosphere, encourage employees to communicate closely in private, and carry out social interactions other than formal work, thereby enhancing the personal relationship between employees, improving the transparency of corporate information, promoting exchange of resources, and enabling the communication of employees is more free and efficient, so it is given more authority and resources to deal with the problems in the work, and ultimately promote more innovative behavior of employees.

\subsection{Research Limitations and Future Research Directions}

Although this study adds the mediating effect of job embeddedness and the moderating effect of internal social capital on the basis of the direct effect of psychological capital on innovative behavior, it enriches the source of variables 
and enriches the research mechanism of psychological capital on individual behavior, but still has the following insufficient: First, the study collected multi-source data from three time periods, but strictly speaking, this study is not a vertical study in the true sense, and the data is mainly from the subjective report of the sample, although the researchers have the bias controlled, but the bias still exists. Therefore, future research can use longitudinal tracking design, combined with field experiments and laboratory experiments, to improve the accuracy of the research results to improve the external validity of the research conclusions. Second, the sample of this study mainly comes from South China, so the research results are applicable. Further testing is needed in other regions or samples, so future research can expand the scope of sampling and increase the sample size to verify the external validity of the conclusions of this study. It is also necessary to verify the conclusions of this study for specific research samples. Third, this study only explores the mediating role of job embeddedness, but there may be other influencing factors between psychological capital and innovative behavior. Therefore, future research can add other variables to further clarify the relationship between psychological capital and innovative behavior, and clarify the principle the effect of psychological capital. In addition, other contextual factors (such as leadership style, organizational culture) that are common in organizations are also very valuable in how to regulate the process of psychological capital to stimulate innovative behavior.

\section{Conflicts of Interest}

The author declares no conflicts of interest regarding the publication of this paper.

\section{References}

[1] Shin, S.J., Yuan, F. and Zhou, J. (2016) When Perceived Innovation Job Requirement Increases Employee Innovative Behavior: A Sense-Making Perspective. Journal of Organizational Behavior, 38, 68-86. https://doi.org/10.1002/job.2111

[2] Woods, S.A., Mustafa, M.J., Anderson, N. and Sayer, B. (2018) Innovative Work Behavior and Personality Traits: Examining the Moderating Effects of Organizational Tenure. Journal of Managerial Psychology, 33, 29-42.

https://doi.org/10.1108/JMP-01-2017-0016

[3] Sweetman, D., Luthans, F., Avey, J. and Luthans, B.C. (2011) Relationship between Positive Psychological Capital and Creative Performance. Canadian Journal of Administrative Sciences, 28, 4-13. https://doi.org/10.1002/cjas.175

[4] Sameer, Y.M. (2018) Innovative Behavior and Psychological Capital: Does Positivity Make Any Difference. Journal of Economics and Management, 32, 76-101. https://doi.org/10.22367/jem.2018.32.06

[5] Luthans, F., Youssef, C.M. and Avolio, B.J. (2007) Psychological Capital: Developing the Human Competitive Edge. Oxford University Press, Oxford.

[6] Luthans, F., Youssef, C.M. and Rawski, S.L. (2011) A Tale of Two Paradigms: The Impact of Psychological Capital and Reinforcing Feedback on Problem Solving and Innovation. Journal of Organizational Behavior Management, 31, 333-350. 
https://doi.org/10.1080/01608061.2011.619421

[7] Yang, H.C. and Cho, H.Y. (2015) Small and Medium Business Workers' Positive Psychological Capital, Life Satisfaction, and Innovative Work Behavior. Journal of Distribution Science, 13, 25-31. https://doi.org/10.15722/jds.13.7.201507.25

[8] Avey, J.B., Wernsing, T.S. and Luthans, F. (2008) Can Positive Employees Help Positive Organizational Change? Impact of Psychological Capital and Emotions on Relevant Attitudes and Behaviors. The Journal of Applied Behavioral Science, 44, 48-70. https://doi.org/10.1177/0021886307311470

[9] Choi, S.B. (2018) Positive Psychological Capital and the Innovative Behavior: The Mediating and Moderating Roles of Self-Leadership. Korean Association of Human Resource Development, 6, 165-187. https://doi.org/10.24991/KJHRD.2018.06.21.2.165

[10] Hobfoll, S.E. (2002) Social and Psychological Resources and Adaptation. Review of General Psychology, 6, 307-324. https://doi.org/10.1037/1089-2680.6.4.307

[11] Mitchell, T.R., Holtom, B.C., Lee, T.W., Sablynski, C.J. and Erez, M. (2001) Why People Stay: Using Job Embeddedness to Predict Voluntary Turnover. Academy of Management Journal, 44, 1102-1121. https://doi.org/10.5465/3069391

[12] Feldman, D.C. and Ng, T.W. (2007) Careers: Mobility, Embeddedness, and Success. Journal of Management, 33, 350-377. https://doi.org/10.1177/0149206307300815

[13] Du, P.C., Li, M., Ni, Q. and Wu, T. (2015) Investigating the Effect of Error Aversion Culture on Employees' Innovative Behavior. Chinese Journal of Management, 12, 538-545.

[14] Lee, T.W., Mitchell, T.R., Sablynski, C.J., Burton, J.P. and Holtom, B.C. (2004) The Effects of Job Embeddedness on Organizational Citizenship, Job Performance, Volitional Absences, and Voluntary Turnover. Academy of Management Journal, 47, 711-722. https://doi.org/10.2307/20159613

[15] Ng, T.W.H. and Feldman, D.C. (2009) Occupational Embeddedness and Job Performance. Journal of Organizational Behavior, 30, 863-891. https://doi.org/10.1002/job.580

[16] Pastoriza, D., Arino, M.A., Ricart, J.E. and Canela, M.A. (2015) Does an Ethical Work Context Generate Internal Social Capital? Journal of Business Ethics, 129, 77-92. https://doi.org/10.1007/s10551-014-2145-4

[17] Adler, P.S. and Kwon, S.W. (2002) Social Capital: Prospects for a New Concept. Academy of Management Review, 27, 17-40. https://doi.org/10.5465/amr.2002.5922314

[18] Nahapiet, J. and Ghoshal, S. (1998) Social Capital, Intellectual Capital, and the Organizational Advantage. Academy of Management Review, 23, 242-266. https://doi.org/10.5465/amr.1998.533225

[19] Luthans, F., Youssef, C.M., Sweetman, D.S. and Harms, P.D. (2013) Meeting the Leadership Challenge of Employee Well-Being through Relationship Psycap and Health Psycap. Journal of Leadership \& Organizational Studies, 20, 118-133. https://doi.org/10.1177/1548051812465893

[20] Luthans, F. and Youssef-Morgan, C.M. (2017) Psychological Capital: An Evidence-Based Positive Approach. Annual Review of Organizational Psychology and Organizational Behavior, 4, 339-366. https://doi.org/10.1146/annurev-orgpsych-032516-113324

[21] Halbesleben, J.R.B., Neveu, J.P., Paustian-Underdahl, S.C. and Westman, M. (2014) Getting to the "COR": Understanding the Role of Resources in Conservation of Re- 
sources Theory. Journal of Management, 40, 1334-1364.

https://doi.org/10.1177/0149206314527130

[22] Luthans, F., Avey, J.B., Smith, R.C. and Li, W.X. (2008) More Evidence on the Value of Chinese Workers' Psychological Capital: A Potentially Unlimited Competitive Resource? International Journal of Human Resource Management, 19, 818-827. https://doi.org/10.1080/09585190801991194

[23] Wright, T.A. (2010) Positive Organizational Behavior: An Idea Whose Time Has Truly Come. Journal of Organizational Behavior, 24, 437-442. https://doi.org/10.1002/job.197

[24] Youssef-Morgan, C.M. and Luthans, F. (2015) Psychological Capital and Well-Being. Stress and Health, 31, 180-188. https://doi.org/10.1002/smi.2623

[25] Avey, J.B., Luthans, F., Smith, R.M. and Palmer, N.F. (2010) Impact of Positive Psychological Capital on Employee Well-Being over Time. Journal of Occupational Health Psychology, 15, 17. https://doi.org/10.1037/a0016998

[26] Wu, W.J., Liu, Y., Lu, H. and Xie, X.X. (2012) The Chinese Indigenous Psychological Capital and Career Well-Being. Acta Psychologica Sinica, 44, 1349-1370. https://doi.org/10.3724/SP.J.1041.2012.01349

[27] Avey, J.B., Reichard, R.J., Luthans, F. and Mhatre, K.H. (2011) Meta-Analysis of the Impact of Positive Psychological Capital on Employee Attitudes, Behaviors, and Performance. Human Resource Development Quarterly, 22, 127-152. https://doi.org/10.1002/hrdq.20070

[28] Zhong, L.F. (2007) Effects of Psychological on Employees' Performance, Organizational Commitment and Organizational Citizenship Behavior. Acta Psychologica Sinica, 39, 328-334.

[29] Lian, X., Yang, B.Y. and Ma, Y.T. (2013) The Effect of Organizational Innovative Climate on Employees' Innovative Behavior: The Mechanism of Individual Factors and Work Characteristics. Chinese Journal of Management, 10, 985.

[30] Wang, J., Yang, J. and Xue, Y. (2017) Subjective Well-Being, Knowledge Sharing and Individual Innovation Behavior. Leadership \& Organization Development Journal, 38, 1110-1127. https://doi.org/10.1108/LODJ-10-2015-0235

[31] Yao, X., Lee, T.W., Mitchell, T.R., Burton, J.P. and Sablynski, C.J. (2004) Job Embeddedness: Current Research and Future Directions. In: Griffeth, R. and Hom, P., Eds., Understanding Employee Retention and Turnover, Information Age, Greenwich, 153-187.

[32] Crossley, C.D., Bennett, R.J., Jex, S.M. and Burnfield, J.L. (2007) Development of a Global Measure of Job Embeddedness and Integration into a Traditional Model of Voluntary Turnover. Journal of Applied Psychological, 92, 1031-1042. https://doi.org/10.1037/0021-9010.92.4.1031

[33] Hobfoll, S.E. (1989) Conservation of Resources-A New Attempt at Conceptualizing Stress. American Psychologist, 44, 513-524.

https://doi.org/10.1037//0003-066X.44.3.513

[34] Halbesleben, J.R.B. and Wheeler, A.R. (2008) The Relative Roles of Engagement and Embeddedness in Predicting Job Performance and Intention to Leave. Work \& Stress, 22, 242-256. https://doi.org/10.1080/02678370802383962

[35] Ng, T.W.H. and Feldman, D.C. (2013) Changes in Perceived Supervisor Embeddedness: Effects on Employees' Embeddedness, Organizational Trust, and Voice Behavior. Personnel Psychology, 66, 645-685. https://doi.org/10.1111/peps.12025

[36] Van Dyne, L. and Lepine, J.A. (1998) Helping and Voice Extra-Role Behaviors: Evi- 
dence of Construct and Predictive Validity. Academy of Management Journal, 41, 108-119. https://doi.org/10.2307/256902

[37] Lin, N. (2002) Social Capital: A Theory of Social Structure and Action. Cambridge University Press, Cambridge, 19. https://doi.org/10.1017/CBO9780511815447

[38] Coleman, J.S. (1988) Social Capital in the Creation of Human Capital. American Journal of Sociology, 94, S95-S120. https://doi.org/10.1086/228943

[39] Chen, M.H., Chang, Y.C. and Hung, S.C. (2010) Social Capital and Creativity in R \& D Project Teams. $R$ \& D Management, 38, 21-34. https://doi.org/10.1111/j.1467-9310.2007.00494.x

[40] Dai, W.L., Zhang, H.Y. and Jin, Y.L. (2012) The Influence of Internal Social Capital on Product Innovation: The Mediating Effect of Knowledge Spiral. Studies in Science of Science, 30, 145-153.

[41] Shaw, J.D., Duffy, M.K., Johnson, J.L. and Lockhart, D.E. (2005) Turnover, Social Capital Losses, and Performance. Academy of Management Journal, 48, 594-606. https://doi.org/10.5465/amj.2005.17843940

[42] Zahra, S.A. (2010) Harvesting Family Firms' Organizational Social Capital: A Relational Perspective. Journal of Management Studies, 47, 345-366. https://doi.org/10.1111/j.1467-6486.2009.00894.x

[43] Dai, Y., Zhu, G.L. and Xiao, D.D. (2011) Internal Social Capital, Knowledge Flows and Innovation-The Empirical Study Based on Enterprises with Provincial Technology Center. Studies in Science of Science, 29, 1046-1055.

[44] Avey, J.B., Luthans, F. and Jensen, S.M. (2010) Psychological Capital: A Positive Resource for Combating Employee Stress and Turnover. Human Resource Management, 48, 677-693. https://doi.org/10.1002/hrm.20294

[45] Hobfoll, S.E. (2001) The Influence of Culture, Community, and the Nested-Self in the Stress Process: Advancing Conservation of Resources Theory. Applied Psychology, 50, 337-421. https://doi.org/10.1111/1464-0597.00062

[46] Portes, A. (1998) Social Capital: Its Origins and Applications in Modern Sociology. Annual Review of Sociology, 24, 1-24. https://doi.org/10.1146/annurev.soc.24.1.1

[47] Sun, L.Y. and Pan, W. (2010) HR Practices Perceptions, Emotional Exhaustion, and Work Outcomes: A Conservation-of-Resources Theory in the Chinese Context. Human Resource Development Quarterly, 19, 55-74. https://doi.org/10.1002/hrdq.1225

[48] Brislin, R.W. (1980) Translation and Content Analysis of Oral and Written Material. In: Triandis, H.C. and Berry, J.W., Eds., Handbook of Cross-Cultural Psychology Methodology, Allyn and Bacon, Boston, Vol. 2, 389-444.

[49] Zhang, H. and Tian, M.F. (2007) Application of Reliability Analysis in Questionnaire Design. Statistics \& Decision, No. 21, 27-29.

[50] Luo, S.Q. and Jiang, Y. (2014) Research Methods of Management Questionnaire Survey. Chongqing University Press, Chongqing.

[51] Scott, S.G. and Bruce, R.A. (1994) Determinants of Innovation Behavior: A Path Model of Individual Innovation in the Workplace. Academy of Management Journal, 37, 580-607. https://doi.org/10.2307/256701

[52] Reed, K.K., Lubatkin, M. and Srinivasan, N. (2006) Proposing and Testing an Intellectual Capital-Based View of the Firm. Journal of Management Studies, 43, 867-893. https://doi.org/10.1111/j.1467-6486.2006.00614.x

[53] Podsakoff, P.M. and Organ, D.W. (1986) Self-Reports in Organizational Research: 
Problems and Prospects. Journal of Management, 12, 531-544.

https://doi.org/10.1177/014920638601200408

[54] Zhang, M. and Hu, Z.G. (2015) The Research of Psychological Capital Effects in Management: Retrospect and Prospect. Journal of Business Economics, No. 4, $32-42$. 